\section{ЯКУТСКИЕ ЦЕННОСТИ В НАЧАЛЕ ХХI ВЕКА}

\section{YAKUT VALUES AT THE BEGINNING IN $21^{\text {ST }}$ CENTURY}

\section{Ульяна А. Винокурова}

Арктический государственный институт культуры и искусств; Северо-Восточный федеральный университет им. М. К. Аммосова, Россия

\author{
Uliana A. Vinokurova \\ Arctic State Institute of Culture and Arts; \\ M. K. Ammosov North-Eastern Federal \\ University, Russia
}

В статье представлено исследование цеенностей народа саха - якутов в их современном состоянии. Этнические ценности, сохраняя сущностную неизменность, подвержены межкультурной и внутрикультурной вариативности и со временем могут переструктуироваться в новые иерархические структуры в зависимости от изменения функционального или смыслового значения. Решается научная проблема выделения и изучения ценностей этнической культуры, являющихся значимыми и достаточными для сохранения национального самосознания и тождества иелостности этноса. За последние 25 лет отмечается усиление этнокультурной идентичности народов Якутии. Общие ценности населения республики, под которыми понимается интеграция ценностей северной солидарности, единства с природой, заботы о детях и старых, трудолюбия и

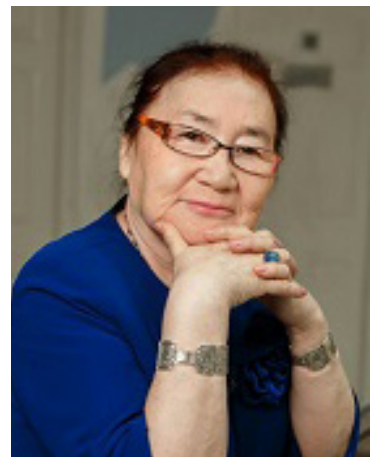

The article presents a study of values of the Sakha people (Yakuts) in the contemporary state of the ethnicity. While the core of ethnic values is still sacrosanct, they are not immune from intercultural and intracultural variation, and eventually can be reshaped into new hierarchic structures according to a shift in functional and conceptual bearing. The article outlines and analyzes the significant values of ethnic culture which are sufficient for preserving the national self-consciousness and integrity of an ethnos. In the last 25 years, there was a marked rise in ethnocultural identity of the peoples of Yakutia. Values shared by these peoples, which we understand as an integration of the values of northern solidarity, consonance with nature,

Винокурова Ульяна Алексеевна - кандидат психологических наук, доктор социологических наук, профессор, доцент, руководитель научно-исследовательского центра циркумполярной цивилизации Арктического государственного института культуры и искусств; профессор кафедры социологии и управления персоналам Северо-Восточного федерального университета им. М. К. Аммосова. Адрес: 677007, Россия, г. Якутск, ул. Октябрьская, д. 3, кв. 16. Тел.: +7 (4112) 34-44-60. Эл. адрес: uottaah1707@gmail.com

Vinokurova Uliana Alekseevna, Candidate of psychology, Doctor of sociology, Professor and Chair, Research Center of Circumpolar Civilization, Arctic State Institute of Culture and Arts; Professor, Department of sociology and human resources, M.K. Ammosov North-Eastern Federal University. Address: Apt. 16, 3 Oktyabrskaya St., Yakutsk, Russian Federation 677007. Tel.: +7 (4112) 34-44-60. E-mail: uottaah1707@gmail.com 
уважения к многообразию культур и языков, вступают во взаимодействие с новыми тенденциями инновационного развития Якутии.

В статье анализируются данные трех масштабных мониторингов - социологических исследований, которые проводились коллективом Института социологии РАН в ряде регионов России, в том числе в Якутии: 1993-1994 г2., 1997-1999 г2. и в 2012 г. Анализ показывает, что одной из ведущих социальных цеенностей в Якутии остается локальная и этническая солидаризация, основой которой саха-якуты прежде всего называли возрождение и развитие национальной культуры, языка, развитие экономики и преодоление социального неравенства и др.

Применение Indigenous Methodology к материалу якутской культуры позволило автору выявить одну из фундаментальных цзенностей самосохранения народа саха - идею парности в следующих проявлениях: мужчина-женщина, человек-животное, человек - место жительства и человек-социум.

Ключевые слова: ценности; саха; якуты; парность; этническая идентичность; социологический опрос; коренные народы; Якутия; indigenous methodology taking care of children and elderly, diligence and respect for variety of cultures and languages, are now interacting with new trends of innovative development of Yakutia.

The article examines the data collected in three wide-scale sociological surveys, conducted by the Institute of sociology of Russian Academy of Sciences in a number of Russian regions, including Yakutia, in 1993-1994, 1997-1999 and 2012, respectively. Our analysis showed that one of the main societal values in Yakutia is the local ethnic self-identification. According to survey responses, it is rooted in the revival and development of national culture, language, economic progress and overcoming the social disparity.

Applying indigenous methodology to the study of Yakut culture helped the author outline one of the values most fundamental for self-protection of the people of Sakha: an idea of duality most often found in such oppositions as man/woman, human/ animal, human/domicile and human/society.

Keywords: values; Sakha; Yakuts; duality; ethnic identity; sociological survey; indigenous people; Yakutia; indigenous methodology

\section{Введение}

В начале XXI века Якутия выходит из многовековой изоляции и стоит на пороге крупных преобразований, вступая в трансконтинентальные потоки ресурсов, транспорта, энергетики, миграции, информации, технологий, идей. Наступает исторический момент, когда Якутия обручится железнодорожным кольцом с экономикой России; в перспективе Северный морской путь введет Якутию в межконтинентальный глобальный мир. Прорабатываются долгосрочные стратегии до 2050 года. Якутия становится стратегическим партнером, играющим ключевую роль в развитии всей Российской Федерации в северовосточном направлении Евразии. Сбудется пророческое предвидение гениального русского ученого М. В. Ломоносова о том, что Российское могущество будет прирастать Сибирью и Северным Ледовитым океаном. Такие глобальные преобразования требуют духовной подготовки к новому геополитическому и геокультурному положению Якутии, чтобы оказаться на гребне несущей волны открытого мира. Верно утверждение, что народ, не имеющий единого национального духа, устойчивых духовных ценностей - это народ без будущего. 
За последние 25 лет отмечается усиление этнокультурной идентичности народов Якутии. Именно общие ценности населения республики, под которыми мы понимаем интеграцию ценностей северной солидарности, единства с природой, заботы о детях и старых, трудолюбия и уважения к многообразию культур и языков, вступают во взаимодействие с новыми тенденциями инновационного развития Якутии.

Мы полагаем, что этнические ценности, сохраняя сущностную неизменность, подвержены межкультурной и внутрикультурной вариативности и со временем могут переструктуироваться в новые иерархические структуры в зависимости от изменения функционального или смыслового значения этих ценностей. Возникает научная проблема выделения и изучения ценностей этнической культуры, являющихся значимыми и достаточными для сохранения национального самосознания и тождества целостности этноса. Идея стабильности культурных ценностей особенно проблематична для народов, ведущих бикультуральный образ жизни - кочевой и оседлый. Хотя значительная часть земной суши заселена именно такими народами, их менталитет остается мало малоизученным.

Ценности этнических общностей пронизывают всю структуру их этнического самосознания. Все социальные компоненты взаимодействия общностей с окружающей социально-природной средой определяются иерархической структурой ценностей, выработанных в процессе исторических судеб народов. Ассимиляция, инкультурация какого-либо составляющего этой структуры ведет к деформации самосознания всего этноса, что негативно влияет на его жизнестойкость. А, с другой стороны, как справедливо отмечает тувинский философ Ч. К. Ламажаа, российская трансформация сопровождается реставрацией архаизации, традиционализма, неотрадиционализма. При этом архаизация общества имеет принципиальные отличия от традиционализма и неотрадиционализма. Традиционализм характеризуется ориентацией общества на сохранение традиций и приверженностью им, которые могут быть сформированы в любой исторический период. Архаизация же обращена к конкретному - древнему архаическому культурному опыту. Неотрадиционализм представляет собой сознательную деятельность по возрождению традиций, использованию их в новых условиях для определенных социальных целей, тогда как архаизация отличается неосознанностью мотивации, поведения масс (Ламажаа, 2011: 12).

Устойчивое развитие этноса возможно при условии сочетания этих трех видов моделей жизнедеятельности в процессе естественно-исторических изменений природных и социальных факторов, сформировавших данный этнос. Модель ответа на вызовы конструируется интеллектуальной элитой этноса как самостоятельный выбор стратегии выживания, развития и самореализации в культурно-историческом пространстве (Винокурова, 1995: 17). 


\section{Ценности саха в социально-историческом контексте}

Народ саха является так называемой титульной нацией в Республике Саха (Якутия). По результатам Всероссийской переписи населения 2010 г. в России проживало 478,1 тыс. якутов, главным образом, в Якутии (466,5 тыс. чел.), Иркутской, Магаданской областях, Хабаровском и Красноярском краях.

Якуты являются наиболее многочисленным (49,9\% населения) народом в Якутии и самым крупным из коренных народов Сибири в границах РФ. За межпереписной период доля сельского населения выросла с 33 до 36\% за счет сохранения ценности чадолюбия, что выразилось в естественном приросте, несмотря на низкое качество сельской жизни в соответствии с социальными индикаторами благополучия. Согласно прогнозам Независимого института социальной политики, при сохранении тенденций переходного периода численность якутов превысит половину населения в ближайшие годы (Республика Саха ..., Электр. ресурс).

Известно, что этногенез покоится на трех компонентах - историкокультурном, языковом и антропологическом. С этой точки зрения, оседлое скотоводство, сочетающееся с рыболовством и охотой, жилища и хозяйственно-бытовые постройки, одежда, обувь, орнаментальное искусство, религиозно-мифологические воззрения якутов имеют южносибирскую, в своей основе тюркскую платформу. Устное народное творчество, народные знания, обычное право, имея тюркско-монгольское происхождение, окончально сформировались в бассейне Средней Лены (Гоголев, 1993: 125).

В настоящее время преобладают научные концепции, стремящиеся доказать, что народ саха имеет сложное этногенетическое происхождение, вобрав в себя тюркские, монгольские, палеоазиатские племена и сформировался как этнос на долинах Средней Лены, на территории современной Якутии. Его язык относится к тюркским, в котором около $25 \%$ слов имеют монгольское происхождение, около 4\% слов заимствованы из тунгусо-маньчжурских языков, около $10 \%$ слов неустановленного происхождения (там же). Этот народ длительное время оставался скотоводческим, путем народной селекции выведшим аборигенные породы домашнего скота и лошадей, тем самым обеспечивший себе некоторую независимость от экстремальных природно-географических условий.

Пожалуй, народ саха - единственный этнос-глобализатор на планете, мирно заселивший огромные территории с экстремальными природными условиями и сохраняющий свою культурную целостность и единое этническое самосознание на протяжении многих веков. Он сменил одним за другим несколько типов стратегий жизнеобеспечения в условиях природно-культурных кормящих ландшафтов степи, гор, тайги, тундры, аласов, городов. И эта поливариантность стратегий усиливает жизнестойкость этноса, исповедующего панпсихизм (единство материального и идеального), экософию, что формирует ценности 
Добра, Мира, Света, Красоты. Эта особенность менталитета саха тормозит формирование востребованных ныне ценностей и намерений к достижению конкурентных меркантильных целей обогащения, поклонения Золотому тельцу.

Истоки такой ментальности можно обнаружить в исторических памятниках. Одним из самих древних и неопровержимых духовных посланий потомкам саха являются рисунки наскального искусства, обнаруживаемые далеко за пределами Полярного круга. Сакральный мир предков несет в себе заряд их духовного могущества: магическую силу, священный смысл, репрезентативную идентичность вещам космического значения, символическую ценность.

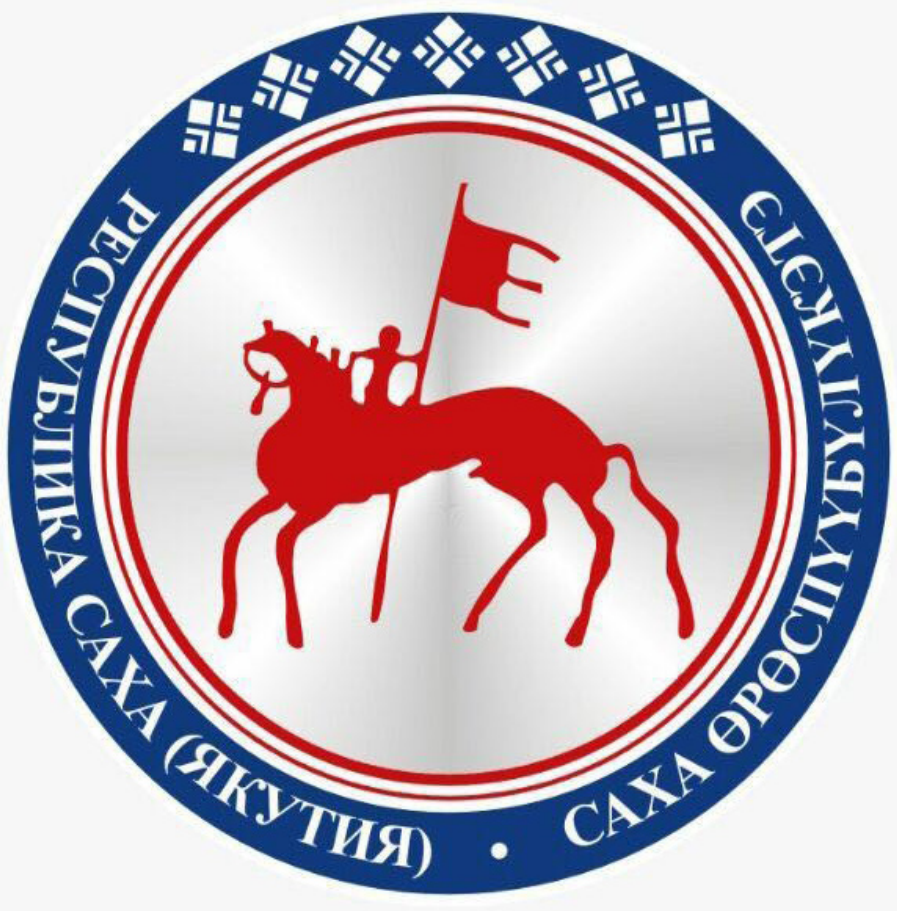

Рис. 1. Герб Республики Саха (Якутия).

Своеобразным символом этнической судьбы народа саха является образ всадника со знаменем на Гербе Республики Саха (Якутия) (см. рис. 1), прообразом которого послужил рисунок на Шишкинских писаницах вблиз села Качуг Иркутской области. Академик А. П. Окладников доказал, что Шишкинские писаницы созданы в VI-IX вв. нашей эры курыканами - предками якутов (Окладников, 1959). Главная отличительная черта этих рисунков - они сугубо мирные. А.П. Окладников утверждал, что Шишкинские скалы - это скальная летопись исторического прошлого Прибайкальских племен, своеобразной энциклопедии культуры и искусства Прибайкалья с древнейших времен до XVII - до XVIII в.в. Здесь запечатлены художественными средствами трансформация мироощущения людей с древнейших веков, образы, символы и смыслы картины мира древней тюркоязычной народности, занимавшейся скотоводством и земледелием, имеющей фонетическую письменность (Окладников, 1951).

Всадник на Гербе Республики Саха - символ объединения людей, народов на современную историческую эпоху живущих в республике. Под этим знаменем они объединяют свои ценности, труд, знания и опыт для обеспечения подлинной государственности суверенной Республики Саха (Якутия). Преем- 
ственность ценностей мира, зафиксированных в древнем искусстве, в стратегии жизнеобеспечения обнаруживается и в менталитете современных саха.

В 1993-1994 гг. научным коллективом Института этнологии и антропологии РАН было проведено сравнительное социологическое исследование по проекту “Национальное самосознание, национализм и разрешение конфликтов в Российской Федерации” под руководством ведущего российского этносоциолога Л. М. Дробижевой по единой методике в Татарстане, Северной Осетии, Туве и Якутии. Затем под руководством Л. М. Дробижевой были проведены два крупных исследования: в 1997-1999 гг. по теме «Гражданская, региональная и этническая идентичность и проблемы интеграции российского общества», в 2012 г. - по теме “20 лет реформ глазами россиян”, методология и инструментарий (опросный лист) которых были откорректированы в Центре исследования межнациональных отношений Института социологии РАН вместе с учеными из Республики Саха (Якутия) применительно к исследованию в Саха (Якутия).

Таким образом, мы располагаем данными своеобразного масштабного мониторинга над конструированием конструктов этнического самосознания, в том числе и ценностей.

В данном исследовании этническое самосознание понималось в широком смысле: как осознание принадлежности к своему народу, как представления о его культуре, языке, территории, истории, государственности (Национальное самосознание ... 1994: 31). В анкете исследования были включены вопросы, помогающие установить место этнических ценностей и интересов, соотношения гражданских и этнических ценностей в разных условиях межнациональных взаимодействий. Объективными условиями и показателями функционирования этнических ценностей в исследовании были использованы данные Всесоюзной переписи населения 1989 г., то есть периода перед началом перестройки.

Исследования выявили, что одной из ведущих социальных ценностей в Якутии является локальная и этническая солидаризация, основой которой саха-якуты прежде всего называли «возрождение и развитие национальной культуры», языка (соответственно 68\% и 62\%), затем «развитие экономики и преодоление социального неравенства» - 53\% и «укрепление самостоятельности Республики Саха (Якутия)» - 47\%, и далее «наведение порядка, борьба с коррупцией» (Идентичность и консолидационный ... , 2012: Электр. ресурс). В Республике Саха (Якутия) на первом месте в представлении о счастье остается семья (среди саха-якутов этот выбор сделали 71\%, русских - 74\%). Жить обеспеченно, в достатке мечтают 65\% и саха-якутов, и русских, иметь интересную работу (57\% и 58\% соответственно), пользоваться уважением людей (52\% сахаякутов, 42\% русских), жить без страха (30\% саха-якутов, 40\% русских). В Саха (Якутия) и у саха-якутов, и у русских среди условий счастливой жизни третье мест по значимости занимает утверждение «иметь хорошую, престижную работу». Эту позицию отмечают практически 60\% опрошенных (там же). 
В 1999 г. властям Саха (Якутии) доверяли в целом 30,1\% опрошенных, а общероссийским властям лишь 11,3\% (там же). В 2012 г. в республике отмечается явное повышение доверия республиканской власти. Президенту республики доверяют $76 \%$ саха-якутов и $44 \%$ русских, правительству региона $-70 \%$ сахаякутов и $39 \%$ русских. Правительству РФ доверяют 65\% саха-якутов и $45 \%$ русских (там же). Чувство гордости и достоинства за то, что ты якутянин ощущают 39\% русских. У саха-якутов, естественно, это чувство еще выше - 81\%. Российская идентичность присуща практически 70\% якутянам (67\% саха-якутов, 79\% русских), а ощущение сильной связи у саха-якутов и русских одинаково (45\%).

В середине 1990-х российское сознание фиксировалось у $54 \%$ саха-якутов и $50 \%$ русских. С россиянами якутян, прежде всего объединяет общее государство (86\% саха-якутов и 70\% русских назвали этот интегратор) и ответственность за судьбу страны (44\% саха-якутов, $40 \%$ русских), родная земля, территория, природа (44\% и 51\% соответственно (там же). Этническая солидарность как потребность в принадлежности к своей этнической группе сильнее выражена среди саха-якутов - 56,6\% полагают, что «современному человеку необходимо ощущать себя частью своей национальной группы», в то время как среди русских в республике эту позицию поддерживают лишь $24 \%$ (там же). Исследование в Саха (Якутии) показало, что такие ценности как социальная справедливость, борьба с коррупцией, равноправие являются наиболее востребованными, их в качестве первоочередных мер, необходимых для успешного развития России называли 80-90\% опрошенных (там же).

Территория Республики Саха (Якутия) составляет 3103,2 тыс. кв. км, Численность населения - 1094065, из них 382 тыс. саха в Якутии (Национальное самосознание ..., 1994: 235). Народ саха дисперсно расселен и представляет собой этническое меньшинство в своей родине, прежде всего в промышленных районах. Это обстоятельство требовало больших усилий для этнического самосохранения и устойчивого развития. Данные переписи свидетельствуют об углубляющихся процессах ассимиляции якутских ценностей вмешающей русской культурой: саха, считающие родным языком язык своей национальности - 93,8\%, (соответственно тувинцев - 98,5\%) (там же: 234).

Интеграция в русскую культуру способствовала саха занять профессиональную нишу в управленческих структурах: индекс представительства относительно среднего российского уровня доли занятых в городе: руководители высшего звена - 207 (для сравнения: у тувинцев - 150), руководители среднего звена - 64 (у тувинцев - 46), специалисты высшей квалификации - 150 (у тувинцев - 67), специалисты средней квалификации - 151 (у тувинцев - 115), служащие - 135 (у тувинцев - 110) (там же: 245).

Таким образом, у саха усиливаются возможности использовать механизмы влияния на регионализацию трансформационных процессов в России и конструирование адекватных вызовам времени ценностей жизнеутверждения. 


\section{Indigenous methodology в исследовании ценностей коренных народов}

Indigenous Methodology как методологическая парадигма для исследования коренных народов направлена на обогащение науки мышлением, практикой, интерпретацией менталитета коренных народов их собственными учеными (indigenous scholars) с целью обеспечить лучшее понимание и принятие коренных народов как субъектов истории, имеющих богатое культурное и интеллектуальное, аксиологическое наследие и современный потенциал этнического развития (Chilisa, 2000).

В настоящее время актуализируются проблемы цивилизационного насилия, процессы сопротивления доминированию, модернизации этнической идентичности, ценностей и образа жизни коренных народов под давлением новых вызовов социального, геополитического и природно-экологического характера, цивилизационных и планетарных процессов человечества. Повестка дня для коренных народов состоит в создании условий формирования их способности реагировать адекватно на крупнейшие цивилизационные перемены и преобразование образа жизни биосферного общества в условиях экологической трансформации Земли и смены технологических укладов. Миро-системный анализ трансформации общества, предпринятый И. О. Новожиловой, позволил ей выявить ценности социоэкологических типов обществ, утверждать, что ценностное отношение к природе экосистемных обществ становятся востребованными в формирующемся ноосферном обществе (Новожилова, 2012).

Концептуализация понятий «социоэкологическая трансформация» и «исторический тип социально-экологической системы», предпринимаемая социальными экологами, усиливает позиции социогуманитарных исследований ценностей коренных народов. Наиболее активные социогуманитарные исследования ведутся по экологическим и космологическим знаниям кочевниковоленеводов, коневодов, скотоводов, шаманизму, лингвистической и этнокультурной идентичности коренных народов как представителей экосистемных сообществ. Методология этих исследований разрабатывается преимущественно с позиций outside. Проекты ведутся по методологии западных и восточных партнеров, а коренные исследователи, как представители коренных народов, не могут в полной мере реализовать «взгляд изнутри» (inside), то есть под парадигмой Indigenous Methodology, использовать полученные знания для улучшения понимания и управления судьбами коренных народов (Kovach, 2010).

Научные исследования, инициируемые и выполняемые коренными учеными в русле направления Indigenous Methodology, проводятся в Новой Зеландии, Норвегии, Финляндии, Канаде, Гавайе, Австралии, в странах Африки. Indigenous Methodology формируется не только как научная методология, но и становится идеологией ревитализации этнической идентичности коренных народов. В 
Якутии основы Indigenous Methodology заложил И. А. Аргунов (Аргунов, 1985), создавший сектор комплексных социологических исследований в академическом институте и отстаивавший достоинство и исконные ценности народов Якутии в период советской трансформации социальных отношений. Доктор медицинских наук, профессор с творческой гражданской позицией, унаследовавший ценности северных саха, М. А. Тырылгин аргументированно опроверг концепцию вымирания и исторической обреченности народа саха, довлеющую над умами многих европейских исследователей XIX и XX века (Тырылгин, 2000). Междисциплинарные исследования ценностей народа саха, позволивших ему физически и духовно выжить в экстремальных природно-географических условиях «сдвоенного холода» (криолитозона и рекордно низкая температура воздуха в Евразии), могут выявить механизмы сочетания архаизации и модернизации образа жизни коренных народов в условиях экологической трансформации планеты.

Жизнь на Вершине Холода становится источником великого учения о сохранении и творении жизни на планете, Hoто Sapiens экосистемного общества в данных условиях испытал различные уровни коэволюции вместе с трансформацией экологической среды. Социально-духовные ценности (управление собственной судьбой, жизнеспособная культурная целостность и тесное взаимодействие с природой) регулируют социально-экономические системы самоуправления, жизнедеятельность общества и личности, отношения к экологической среде, к образу жизни и этническому самосознанию. Сохраненные ценности экосистемных обществ в условиях Якутии, поддержанные республиканской социальной политикой, способствовали демографическому росту, укорененности на родной земле и защите северной природы от негативного воздействия индустриальных сообществ. Чувствительность к экологическим рискам остается одной из сильных мобилизирующих ценностей саха.

Одной из фундаментальных ценностей самосохранения народа саха, на наш взгляд, является ценность парности в следующих проявлениях: мужчинаженщина, человек-животное, человек-место жительства и человек-социум.

Парность мужчины и женщины является непреложным условием жизни на Севере. Народное творчество наполнено поиском женщины для создания семьи, воспевает значимые качества девушки и юноши для успешного продолжения рода. Выдающийся российский этнопедагог Г. Н. Волков, изучивший этнопедагогические принципы более ста народов России, Европы и Азии, пришел к выводу о необходимости учета парности в современной педагогике. Парность в отношениях «мужчина-женщина», «человек-общество» заложена в этнопедагогических воззрениях народов, ведущих природосообразную жизнь. Г. Н. Волков считал, что главным принципом этнопедагогики является воспитание парности мальчика и девочки. Он полагал, что «традиционная педагогическая мудрость северян представляет собой огромные духовные ресурсы будущего 
человечества. Быть может, именно здесь сохранилось детство человечества в наиболее чистом виде» (Волков, 2002: 348). В этих провидческих мыслях академика Волкова проявлены востребованные ценности экосистемных сообществ в формирующейся ноосферной культуре человечества.

Концепция обновления и развития национальной школы РС (Я) была направлена на формирование активного, жизнедеятельного поколения. Были предусмотрены уроки воспитания мужских качеств и умений у мальчиков «Юрюнг Уолан», женских - у девочек «Кыыс куо». Эти уроки были особенно полезны для мальчиков из неполных семей, которых обучали умению охотиться, выживать в природных условиях Севера. Программы были направлены на воспитание субъектности - домохозяина и домохозяйки, и хозяина, субъекта территории, где они проживают. Формирование локальной идентичности молодых семей залог стабилизации населения на Севере.

Условием выживания северного человека были не только охота, морской промысел и виды присваивающей экономики. Главным было одомашнивание животных: собаки, оленя, коровы, лошади. Якуты, как самые северные скотоводы, придумали формулу парности в данном контексте - кuhu-cүөhy (дословно человек-животное), обозначающее неразрывную связь человека со своим одомашненным животным. Представители оленеводческих народов в один голос твердят, что “есть олень - есть народ, нет оленя - нет народа”. Более того, олень становится символом, объединяющим оленеводческие народы. Удивительный эффект парности “человек-животное” доказало чудесное спасение 4-летней Карины после 12-дневного блуждания в осенней якутской тайге вместе со своим щенком в 2014 г. в Якутии. Только благодаря щенку, согревающему в холодные ночи и составившему живую компанию, маленькая девочка не потеряла никаких психических и физических качеств социализированного ребенка (Таюрский, 2014: Электр. ресурс).

Парность в условиях Севера проявляется также в его отношении к среде обитания. В якутском мировоззрении феномен парности проявляется в понятии дьон-сэргэ (дословно: люди-коновязь), содержательно его можно обозначить словом «со-в-местность». Оно указывает на особенность обустройства, обжитости, укоренения человека на исконной земле, создании домохозяйства на участке, способном приютить от природных ненастий на энергетически благоприятной местности, обеспечить пищей человека и кормами его одомашненных животных. Коновязь символизирует присутствие человека в пространстве, одухотворение этим сакральным сооружением местности, человеческого жилища, стойбища.

Парадоксальность северной политики состоит в том, что она не поддерживает возможность постоянного проживания поздних насельников этих территорий. Политика заселения человека в северных территориях России не учитывает фундаментальный принцип привязанности человека к среде обитания и 
нацелена преимущественно на стимулирование временного проживания мигрантов в северных поселениях, что привело к активному исходу трудоспособного населения в последние 25 лет. Отсутствие ни кола, ни двора, несформированность локальной идентичности у пришлого населения при недостаточности социальных благ и качества жизни ведут к размыванию духовных ценностей, выработанных многовековой адаптацией человека к Северу. Так, арктические территории Якутии потеряли за с 2010 по 2013 г. 15244 человек, что составляет 18\% населения (Республика Саха ..., 2014: 59-60).

Излюбленной темой демографов и педагогов стал гендер, склонный к феминизму. В программах воспитания и образования в дошкольных учреждениях отсутствует принцип парности, как способа формирования половой идентичности и метода воспитания взаимодополняющей созидательности отношений мужчины и женщины. Нарушение этого принципа привело к дисгармонии отношений между мужчиной и женщиной, ставших субъектами конкуренции и отстаивающих противоположные ценности, цели и смыслы. Кризис семьи, половой идентичности, отчуждения человека от общественных обязанностей и воспроизводства межпоколенческой преемственности ролей мужчин и женщин, - во многих ныне наблюдаемых проявлениях социального кризиса пусковым механизмом стало игнорирование или уход от фундаментального принципа парности. Как следствие, осуществляется выбор пути демографической депопуляции общества, так как разъединяется природой заложенная парность как основа жизнеутверждения.

Ценность справедливости является несущей конструкцией социального организма якутского общества. Судебные тяжбы, переходящие от поколения к поколению, были характерны для неграмотного дореволюционного якутского населения. В якутском обычном праве существует свод правил, обычаев, норм, регулирующих межличностные, семейные, родовые, территориальные отношения. Приверженность к речевому этикету, договорным отношениям силой сказанного слова, пристрастная защита доброго имени, борьба за родовые угодья всеми доступными в обычном и гражданском праве средствами, - все эти особенности народного правового сознания саха получили широкий простор для проявления в постперестроечное время. Свобода слова и информации прорвало веками накопленное чувство обиды и несправедливости, совершенные в период насилия красного террора и репрессий.

На укрепление этнических ценностей саха в постперестроечный период сильный импульс оказал Указ Президента РФ Б. Н. Ельцина от 26 апреля 1994 г. “О восстановлении справедливости в отношении репрессированных в 20-30-е годы представителей якутского народа". Доктор философских наук А. Г. Новиков определил следующее значение данного документа: снято несправедливое обвинение не только отдельных людей, но и целого народа; возвращены народу историческая память, доброе имя; созданы идеологические условия для приобщения народа к своему наследию, к национальным ценностям (Новиков, 1996). 94 
Для консолидации общества перед лицом новых вызовов Якутии, для утверждения нового вектора развития - духовного единения - был организован $\mathrm{Pe}-$ спубликанский Форум общественности “Духовный потенциал общества в инновационном развитии Якутии” в День государственности Республики Саха (Якутия) - 27 сентября 2011 г. (Декларация ..., 2011: Электр. ресурс).

Данная декларация основана на нормах Всеообщей Декларации прав человека ООН 1948 г., Декларации прав и свобод человека (утверждена 5 сентября 1991 г. №2393-1 Съездом Народных Депутатов СССР), Пакта Рериха (15 апреля 1935 г.), Декларации прав коренных народов ООН 13 сентября 2008 г., проекта Декларации прав культуры, разработанного Д. С. Лихачевым, Декларации о путях к глобальной этике (принята Парламентом мировых религий в 1993 г., Чикаго).

Текст Декларации духовных ценностей народов Якутии учитывает особенности духовных регуляторов поведения людей, апеллирует к эмоциональной сфере человека, побуждая к доверию. В восприятии текста психологически задействованы рациональный и иррациональный чувственный мир, эмоциональная и интеллектуальная способности человека, подсознательная, бессознательная и надсознательная сфера высших духовных устремлений, образное и логическое мышление. Стиль Декларации намеренно отличается от общепринятых канонов подобных документов, написанных в духе западноевропейского права, апеллирующих к приоритету государства над поведением граждан, человека над средой. В данном документе осуществлен синтез современного права с духом арктического человека, провозглашаются ценности, созданные в условиях агрессивных по отношению к теплокровному человеку природноклиматических условий холода и вечной мерзлоты, то есть приоритет отдается природным условиям жизнеобеспечения и межличностным отношениям, а не государствообразующим нормам.

Ценности данной Декларации являются по сути общечеловеческими по содержанию, в том числе для представителей всех наций, населяющих территорию Якутии, а по форме изложены в лингвокультурологических формулах северной ментальности и мудрости саха, эвенов, эвенков, юкагиров, долган, чукчей и русских-старожилов. Образная интонационность локализует место провозглашения Декларации - Якутию как Север Азиатской России. Северный ракурс является востребованным вектором российского направления развития в XXI веке. Таким образом, достигается, с одной стороны, - узнавание себя и утверждение достоинства коренных народов Якутии, с другой стороны, выражение Голоса Арктики в глобальном мире.

Главной целью данной Декларации является выявление, признание и провозглашение ценностей коренных народов Якутии для упорядочивания и защиты ценностей этнической идентичности и самоидентификации коренных народов, облечения понимания культурных особенностей местного населения мигрантами и внешним миром, установления дружественных отношений между различными социокультурными общностями в Якутии. 
Декларация духовных ценностей народов Якутии стала гражданским волеизъявлением участников Форума общественности, на котором принимали участие 1250 представителей всех районов, конфессий, национальных общин, социально-профессиональных и социально-демографических групп населения республики. Она станет одним из новых механизмов достижения межнационального согласия, толерантных отношений и взаимопонимания ценностей в условиях межцивилизационного, межкультурного пограничья.

\section{Заключение}

Управляемый процесс культурного творения создает основу для оптимизма относительно судеб этносов, находящихся ныне на грани этнической ассимиляции и теряющих условия своего этнического существования. Диссимиляционная политика в Якутии по восстановлению этнически значимых символов, смыслов и ценностей дает эффективные результаты, мобилизуя индогенные социопсихологические резервы и механизмы этнического самосохранения малочисленных коренных народов Севера, находящихся на грани этнокультурной ассимиляции. Народ саха, как титульная нация, берет на себя ответственность за их сохранение и развитие, осознавая, что спасение родственных этнических меньшинств и духовная солидаризация якутян есть своеобразная защита собственного существования.

Следование методологиям социальной антропологии по отношению к конструированию духовных ценностей коренных народов не имеет позитивной перспективы для этих народов прежде всего потому, что духовная культура есть непрерывный процесс. Научное выделение из нее архаических, традиционных, неотрадиционных процессов возможно в теоретических исследованиях, а в живой культуре эти слои находятся в снятом виде и в чистом виде невозможно выделить в практиках этнокультурной жизни коренных народов. Более того, вычленение глубинных ценностей для конструирования иерархии современных ценностей может усилить устойчивость этнического самосознания. Набор привычных в социальной антропологии ценностей недостаточен для ревитализации духовной культуры народа саха. На наш взгляд, ценности солидаризации и парности являются стержнем иерархии духовных ценностей народа саха.

\section{СПИСОК ЛИТЕРАТУРЫ}

Аргунов, И. А. (1985) Социальное развитие якутского народа. Новосибирск : Наука. 318 с.

Винокурова, У. А. (1995) Формирование и изменение ценностных структур сознания народов Якутии : автореф. дисс. ... д-ра соц. н. М. 44 с. 
Волков, Г. Н. (2002) Педагогика любви. Избранные этнопедагогические сочинения. Т. 1. М. : Издат. Дом «Магистр-Пресс». 456 с.

Гоголев, А. И. (1993) Якуты. Проблемы этногенеза и формирования культуры. Якутск: Изд-во ЯГУ. 200 с.

Декларация духовных ценностей народов Якутии (2011) [Электронный ресурс] // Официальный информационный портал Республики Саха (Якутия). 4 ноября. URL: http://old.sakha.gov.ru/node/48626 (дата обращения: 02.07.2017).

Идентичность и консолидационный ресурс жителей республики Саха (Якутия) (2012) [Электронный ресурс]. М. : Институт социологии РАН. 97 с. 1 CD ROM, Официальный сайт Института социологии PAH, URL: http://www.isras.ru/ files/File/INAB/INAB_4_2012.pdf (дата обращения: 02.07.2017).

Ламажаа, Ч. К. (2011) Архаизация общества в период социальных трансформаций (социально-философский анализ тувинского феномена) : автореф.дисс. ... Д-ра филос. н. М. 43 с.

Национальное самосознание и национализм в Российской Федерации начала 1990-х годов (1994) / редколл.: Л. М. Дробижева, А. Р. Аклаев и др. М. : ИЭА PAH.

Новиков, А. (1996) О менталитете саха. Якутск : Аналит. центр при Президенте $\mathrm{PC}(Я) .141 \mathrm{c}$.

Новожилова, Е. О. (2012) Социально-историческая экология. СПб. : НесторИстория. 240 с.

Окладников, А. П. (1951) Конь и знамя на Ленских писаницах // Тюркологический сборник. Т. 1. Отв. ред. А. Н. Кононов. М.-Л. С. 144-154.

Окладников, А. П. (1959) Шишкинские писаницы. Памятник древней культуры Прибайкалья. Иркутск : Вост.-Сиб. кн. изд-во. 210 с.

Республика Саха (Якутия) [Электронный ресурс] // Социальный атлас российских регионов. URL: http://atlas.socpol.ru/portraits/yak.shtml (lата обращения: 1.07.2017).

Республика Саха (Якутия). Статистический справочник (2014). Якутск: Терр. Орган Федеральной службы Гос. Статистики по РС(Я).

Таюрский, В. (2014) Случай выживания девочки в якутской тайге назвали уникальным [Электронный ресурс] // Российская газета. 12 августа. URL: http:// www.rg.ru/2014/08/12/reg-dfo/karina.html (дата обращения: 01.07.2017).

Тырылгин, М. А. (2000) Истоки феноменальной жизнеспособности народа саха. Якутск : Бичик. 304 с.

Chilisa, B. (2012) Indigenous Research Methodologies. London: Sage Publication Ltd. 343 p. 
Kovach, M. (2010) Indigenous Methodologies: Characteristics, Conversations and Context. Toronto: University of Toronto Press.

Дата поступления: 15.07.2017 г.

\section{REFERENCES}

Chilisa, B. (2012) Indigenous Research Methodologies. London, Sage Publication Ltd. 343 p.

Kovach, M. (2010) Indigenous Methodologies: Characteristics, Conversations and Context. Toronto, University of Toronto Press.

Argunov, I. A. (1985) Sotsial'noe razvitie iakutskogo naroda [Social development of the Yakut people]. Novosibirsk, Nauka. 318 p. (In Russ.).

Vinokurova, U. A. (1995) Formirovanie i izmenenie tsennostnykh struktur soznaniia narodov Iakutii [The formation and modification of value structures of consciousness of the peoples of Yakutia]: Thesis of Diss. ... Doctor of Sociology. Moscow. 44 p. (In Russ.).

Volkov, G. N. (2002) Pedagogika liubvi. Izbrannye etnopedagogicheskie sochineniia [The pedagogy of love. Selected ethnopedagogical works]. Moscow, Publ. Haus «MagistrPress». Vol. 1. 456 p. (In Russ.).

Gogolev, A. I. (1993) Iakuty. Problemy etnogeneza i formirovaniia kul'tury [Yakuts. Problems of ethnogenesis and formation of culture]. Iakutsk, IaGU Publ. 200 p. (In Russ.).

Deklaratsiia dukhovnykh tsennostei narodov Iakutii [Declaration of spiritual values of the peoples of Yakutia] (2011). Ofitsial'nyi informatsionnyi portal Respubliki Sakha (Iakutiia), 4 November [online] Available at: http://old.sakha.gov.ru/node/48626 (access date: 02.07.2017). (In Russ.).

Identichnost'i konsolidatsionnyi resurs zhitelei respubliki Sakha(Iakutiia) [Identity and consolidation resources of the people of Republic of Sakha (Yakutia)] (2012). M. : Institut sotsiologii RAN. 97 s. 1 CD ROM, Ofitsial'nyi sait Instituta sotsiologii RAN [online] Available at: http://www.isras.ru/files/File/INAB/INAB_4_2012.pdf (access date: 02.07.2017). (In Russ.).

Lamazhaa,Ch.K.(2011)Arkhaizatsiia obshchestva v period sotsial'nykh transformatsii (sotsial'no-filosofskii analiz tuvinskogo fenomena) [The archaization of society in the period of social transformation (socio-philosophical analysis of the Tuvan phenomenon)]: Thesis of Diss.... Doctor of Philosophy. Moscow. 43 p. (In Russ.).

Natsional'noe samosoznanie i natsionalizm v Rossiiskoi Federatsii nachala 1990$k h$ godov [National identity and nationalism in the Russian Federation in early 1990s] (1994) / (Ed.) L. M. Drobizheva, A. R. Aklaev et al. Moscow, IEA RAN. (In Russ.). 
Novikov, A. (1996) O mentalitete sakha [On the mindset of Sakha]. Iakutsk, Analit. tsentr pri Prezidente RS(Ia). 141 p. (In Russ.).

Novozhilova, E. O. (2012) Sotsial'no-istoricheskaia ekologiia [The socio-historical ecology]. St. Petersburg, Nestor-Istoriia. 240 p. (In Russ.).

Okladnikov, A. P. (1951) Kon' i znamia na Lenskikh pisanitsakh [The horse and the banner on the Lena petroglyphs]. In: Tiurkologicheskii sbornik. Vol. 1. Ed. by A. N. Kononov. Moscow, Leningrad. P. 144-154. (In Russ.).

Okladnikov, A. P. (1959) Shishkinskie pisanitsy. Pamiatnik drevnei kul'tury Pribaikal'ia [Shishkin petroglyphs. A monument of the ancient culture of the Baikal region]. Irkutsk, Vost.-Sib. kn. izd-vo. 210 p. (In Russ.).

Respublika Sakha (Iakutiia) [The Republic Of Sakha (Yakutia)]. Sotsial'nyi atlas rossiiskikh regionov [online] Available at: http://atlas.socpol.ru/portraits/yak.shtml (access date: 1.07.2017). (In Russ.).

Respublika Sakha (Iakutiia). Statisticheskii spravochnik [The Republic Of Sakha (Yakutia). A Statistical Handbook] (2014). Yakutsk, Terr. Organ Federal'noi sluzhby Gos. Statistiki po RS(Ia). (In Russ.).

Taiurskii, V. (2014) Sluchai vyzhivaniia devochki v iakutskoi taige nazvali unikal'nym [A girl's survival in Yakut taiga named unique]. Rossiiskaia gazeta, 12 August [online] Available at: http://www.rg.ru/2014/08/12/reg-dfo/karina.html (access date: 01.07.2017). (In Russ.).

Tyrylgin, M. A. (2000) Istoki fenomenal'noi zhiznesposobnosti naroda Sakha [The origins of the phenomenal vitality of the Sakha people]. Iakutsk, Bichik. 304 p. (In Russ.).

Submission date: 15.07.2017.

\section{Для цитирования:}

Винокурова У. А. Якутские ценности в начале XXI века [Электронный ресурс] // Новые исследования Тувы. 2017, № 3. URL: https:/nit.tuva.asia/nit/article/view/727 (дата обращения: дд.мм.гг.). DOI: 10.25178/nit.2017.3.6

\section{For citation:}

Vinokurova U. A. Yakut values in 21st century. The New Research of Tuva, 2017, no. 3 [on-line] Available at: https://nit.tuva.asia/nit/article/view/727 (accessed: ...). DOI: 10.25178/nit.2017.3.6 